\title{
Emerging trends in the formation and function of tuberculosis granulomas
}

\author{
Geanncarlo Lugo-Villarino ${ }^{1,2} *^{\dagger}$, D. Hudrisier ${ }^{1,2+}$, A. Benard ${ }^{1,2+}$ and Olivier Neyrolles ${ }^{1,2} *$ \\ ${ }^{1}$ CNRS, Institut de Pharmacologie et de Biologie Structurale, Toulouse, France \\ ${ }^{2}$ Institut de Pharmacologie et de Biologie Structurale, Université de Toulouse, Université Paul Sabatier, Toulouse, France
}

\section{Edited by:}

Dov L. Boros, Wayne State University School of Medicine, USA

\section{Reviewed by:}

Hans Acha-Orbea, Center for Immunity and Infection Lausanne, Switzerland

Jean-louis Mege, Aix Marseille Université, France

Jennifer A. Philips, NYU School of

Medicine, USA

\section{*Correspondence:}

Geanncarlo Lugo-Villarino and Olivier Neyrolles, CNRS, Institut de

Pharmacologie et de Biologie

Structurale, 205 Route de Narbonne,

F-31077 Toulouse, France.

e-mail: geanncarlo.lugo@ipbs.fr;

olivier.neyrolles@ipbs.fr

${ }^{\dagger}$ Geanncarlo Lugo-Villarino, D.

Hudrisier and A. Benard have

contributed equally to this work.
The granuloma is an elaborated aggregate of immune cells found in non-infectious as well as infectious diseases. It is a hallmark of tuberculosis (TB). Predominantly thought as a host-driven strategy to constrain the bacilli and prevent dissemination, recent discoveries indicate the granuloma can also be modulated into an efficient tool to promote microbial pathogenesis. The aim of future studies will certainly focus on better characterization of the mechanisms driving the modulation of the granuloma functions. Here, we provide unique perspectives from both the innate and adaptive immune system in the formation and the role of the TB granuloma. As macrophages ( $\mathrm{M} \phi \mathrm{s}$ ) comprise the bulk of granulomas, we highlight the emerging concept of $M \phi$ polarization and its potential impact in the microbicide response, and other activities, that may ultimately shape the fate of granulomas. Alternatively, we shed light on the ability of B-cells to influence inflammatory status within the granuloma.

Keywords: macrophage, B-cells, mycobacteria, tuberculosis, granuloma

\section{INTRODUCTION}

"On the basis of my numerous observations I consider it established that, in all tuberculous affections of man and animals, there occur constantly those bacilli which I have designated tubercle bacilli and which are distinguishable from all other microorganisms by characteristic properties."

With those celebrated words in 1882, Koch announced the discovery of the etiological agent of one of the oldest recorded human afflictions (Koch, 1982). The term "tubercle" refers to an original description by Sylvius (in 1650) of the apparent lung nodules characteristic of the "consumption" disease, which became christened as "tuberculosis (TB)" by Schonlein (in 1839) in recognition of its intricate correlation with these structures (Sakula, 1982). Today, these tubercles are known as granulomas, defined as organized immune cell aggregates that form in response to persistent TB infection (Ramakrishnan, 2012). The cellular composition of TB granulomas includes $\mathrm{M} \phi \mathrm{s}$, neutrophils, monocytes, dendritic cells, B- and T-cells, fibroblasts, and epithelial cells (Russell, 2007; Ramakrishnan, 2012). Moreover, TB granulomas are characterized by a high-turnover rate of their $\mathrm{M} \phi$ population and by specialized differentiations taking place in mature $M \phi s$ such as tightly interdigitated cell membranes that make $M \phi s$ appear either epithelial (Adams, 1974), fusion into multinucleated giant cells (Helming and Gordon, 2007), or differentiation into foamy cells with a high lipid content (Russell et al., 2009). While granulomas have been studied for about 200 years, their role in TB etiology remains unclear. In 1819, Laënnec first proposed granulomas as the cause of TB (Sakula, 1982). Yet, about a century went by before Ghon correlated the presence of a single caseous granuloma in the midregion of the lung with a corresponding nodal involvement (the Ghon complex) and the pathogen's dissemination, thus serving as a marker for latent TB (Dorhoi et al., 2011). In spite of this, subsequent studies and clinical observations established the granuloma as a host-protective structure that "walls off" Mtb to prevent its dissemination, a notion that still predominates. Seminal studies by Ramakrishnan in zebrafish, however, have now evidenced mycobacteria actually exploit the granuloma into a tool for pathogenesis, suggesting its function can be modulated depending on the disease context (Ramakrishnan, 2012). Considering TB is still one of the leading causes of human death due to a single infectious agent, substantial insights into microbe physiology and host defenses rest in the attempt to better understand the mechanisms governing TB granulomas.

Here, we will focus exclusively in the role of $\mathrm{M} \phi$ polarization in the formation and function of TB granulomas. Likewise, we will provide a unique perspective on the significance of B-cells, whose immune-modulatory function has long been ignored in TB.

\section{MACROPHAGE POLARIZATION IN TB GRANULOMAS}

$\mathrm{M} \phi$ polarization is broadly classified into M1 and M2 programs (Goerdt and Orfanos, 1999; Gordon, 2003; Mantovani et al., 2004; Martinez et al., 2009). On one hand, the M1 program is a response to type- 1 inflammatory conditions (e.g., IFN- $\gamma$ ), often associated with intracellular pathogen resistance (Quintana-Murci et al., 
2007; Benoit et al., 2008). IFN- $\gamma$ is mainly responsible for the establishment of the M1 program, granting M $\phi$ s the capacity to kill mycobacteria (Flynn et al., 1993; Ehrt et al., 2001). The pro-

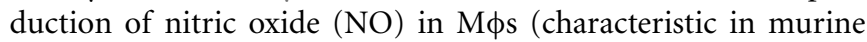
models) is arguably one of the most important consequences mediated by IFN- $\gamma$, as mice deficient for NO production succumb to Mtb infection (Chan et al., 1992). In fact, the enzyme iNOS (inducible NO synthase) required for $\mathrm{NO}$ production is a bona fide marker of murine M1 M $\phi$ s (Xie and Nathan, 1993). Other marker genes, whose expression is induced in $\mathrm{M} 1$, include ido1, ptgs2, il12b/il23a, socs3, marco, cd86, irf3/irf5, and stat1/stat5, among others (Lawrence and Natoli, 2011; Murray and Wynn, 2011b). Collectively, the M1 program is part of the "common host response" against intracellular bacteria that endows $\mathrm{M} \phi$ s with a non-permissible nature (Ehrt et al., 2001; Deretic et al., 2004; Martinez et al., 2009; Cairo et al., 2011; Murray and Wynn, 2011a). On the other hand, the M2 program is dictated by type- 2 inflammatory signals (e.g., IL-4, IL-10), enabling M $\phi$ s to participate in the suppression of inflammation, phagocytosis, tissue remodeling, and repair, among others (Sica et al., 2008; Martinez et al., 2009; Murray and Wynn, 2011a). However, this program also renders $\mathrm{M} \phi \mathrm{s}$ poorly microbicidal against intracellular pathogens (Raju et al., 2008; Martinez et al., 2009). This is best illustrated by how the arginine metabolism is used in M2 M $\phi$ s, which shuts down NO production in favor of tissue reparation (Shearer et al., 1997). Indeed, M2 polarization is accompanied by ARG1 (type-1 arginase) expression that inhibits NO production by outcompeting iNOS to convert arginine into ornithine and urea (Munder et al., 1998; El Kasmi et al., 2008). Along arg1, other M2 marker genes include fizz1, chi311/chi312/chi313, $m r c 1$, cd36, socs2, il-10, klf4, jmjd3/irf4, ppary, and stat6, among others (Lawrence and Natoli, 2011; Murray and Wynn, 2011b). Altogether, Mtb might influence the granuloma function by controlling $\mathrm{M} \phi$ polarization, a premise that is presciently in line with the following findings, which for the purpose of conciseness, are mainly based on the use of the iNOS/ARG1 polarization axis.

The animal models to study TB granulomas are discussed in detail elsewhere (Flynn, 2006). Here, we highlight recent findings in mice and zebrafish documenting the TB granuloma dynamics, supported by studies and clinical observations done in TB patients. It is widely postulated the onset of human pulmonary TB begins when inhaled Mtb is captured by M $\phi$ s and transported across the alveolar epithelium into the lung tissue. In zebrafish, the subsequent steps leading to a nascent granuloma have been captured in real-time imaging (Davis et al., 2002). While infected $\mathrm{M} \phi$ s undergo apoptosis, they promote the recruitment of phagocytes, which upon arrival, display high motility conducive for scavenging apoptotic cells. The phagocytosis of dead M $\phi$ s leads to the formation of cell aggregates, fomenting bacterial growth. Subsequent rounds of this cycle promote the formation of a stable granuloma in 3 days post-infection (p.i.), a process that is dependent on the region of difference-1 (RD1) virulence locus of M. marinum and independent of T-cells (Davis et al., 2002; Volkman et al., 2004, 2010; Davis and Ramakrishnan, 2009). It is unclear whether zebrafish M $\phi$ s undergo polarization. Yet, since most transcription factors governing T-cell polarization are highly conserved in zebrafish (Mitra et al., 2010), along with physiological and pathological responses characteristic of type-1 and type-2 immunity (Aggad et al., 2010; Balla et al., 2010; Holt et al., 2011; Wittamer et al., 2011; Renshaw and Trede, 2012), it seems as a matter of time before $\mathrm{M} \phi$ polarization is identified and characterized in this teleost. By contrast, the early stage of Mtb infection in mice is marked by M1 M $\phi$ polarization, reminiscent of clinical observations in TB patients (Benoit et al., 2008). In fact, transcriptomic analysis of infected murine $\mathrm{M} \phi \mathrm{s}$ revealed the gene modulation provoked by Mtb overlaps with that of IFN- $\gamma$ to establish the M1 program (Ehrt et al., 2001). Type-1 inflammatory signals secreted by infected $\mathrm{M} \phi$ s induce cell recruitment and formation of primary granulomas. Unlike zebrafish, however, granuloma formation in mice takes up to 3 weeks when Mycobacterium reaches a plateau and coincides with adaptive immunity involvement. For instance, nascent liver granulomas were visualized by intravital microscopy between 2 and 3 weeks after Mycobacterium bovis Calmette-Guerin (BCG) challenge (Egen et al., 2011). In another study, Mtb infection did not change the murine $\mathrm{M} \phi$ population (iNOS ${ }^{\text {low }} \mathrm{ARG} 1^{\text {low }}$ ) in bronchoalveolar lavage (BAL) during the first week (Redente et al., 2010). At day 21 p.i., however, M1 M $\phi s$ (iNOS ${ }^{\text {high }} A R G 1^{\text {low }}$ ) dominated in BAL and granulomas, coinciding with a peak of IFN- $\gamma$ in infected lungs (Redente et al., 2010). In humans, although NO production by monocyte-derived $\mathrm{M} \phi$ s remains controversial, both iNOS and NO are detected in granulomas and alleles for NOS2 are associated to TB susceptibility (Nicholson et al., 1996; Facchetti et al., 1999; Choi et al., 2002; Schon et al., 2004; Moller et al., 2009). After 35-60 days p.i., while murine $\mathrm{M} \phi s$ at the granuloma core remained iNOS ${ }^{\text {high }} \mathrm{ARG} 1^{\text {low }}$, there was a dramatic shift toward the M2 program (iNOS ${ }^{\text {low }} A R G 1^{\text {high }}$ ) in M $\phi$ s surrounding the core, accompanied by elevated type- 2 inflammatory signals (Redente et al., 2010). This is in line with ARG1 detection in human TB granulomas (Pessanha et al., 2012).

The shift toward M2 M $\phi$ s during Mtb infection could have deleterious consequences for the granuloma as a host-protective structure (Figure 1). First, ARG1 expression in uninfected M $\phi s$ surrounding the granuloma core suggests the development of an immunosuppressive niche. Indeed, Mtb promotes its survival by inducing ARG1 expression through MyD88-dependent signaling pathways (El Kasmi et al., 2008; Qualls et al., 2010). At the transcriptome level, murine M2 M $\phi$ s displayed a diminished inflammatory response to $\mathrm{Mtb}$ as reflected by a reduced $\mathrm{NO}$ production and increased of iron availability, alluding ARG1 might also be implicated in nutrient deprivation mechanisms limiting microbial growth (Forbes and Gros, 2001; Kahnert et al., 2006; Cairo et al., 2011). Furthermore, M1 M $\phi$ s possess a "fail-safe" system sustaining optimum NO production based on citrulline recycling via argininosuccinate synthase (ASS1), which is absent in M2 M $\phi s$ (Qualls et al., 2012). Given the restrictive granuloma environment where arginine may be limited, the presence of this fail-safe system may become further accentuated. Second, M2 M $\phi$ s may represent a transitional state into the formation of "foamy" $\mathrm{M} \phi \mathrm{s}$ that are rich in cholesterol, a carbon source for microbial intracellular survival (Pandey and Sassetti, 2008; Peyron et al., 2008; Russell et al., 2009; Griffin et al., 2011). Recently, Mtb lipids were shown to trigger PPAR $\gamma$, the master regulator of $\mathrm{M} 2$ polarization, to increase expression of CD36 and induce foam cell formation 


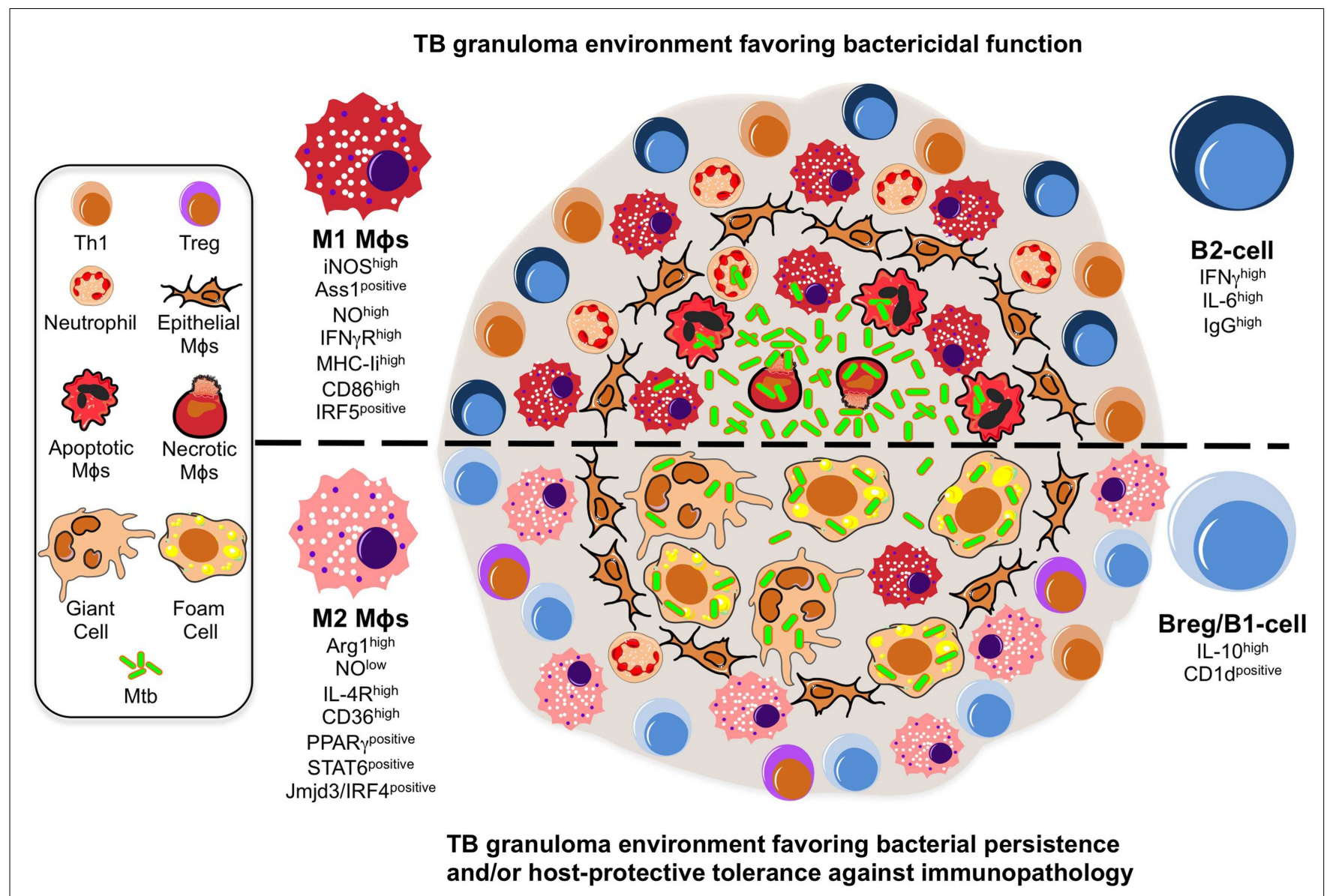

FIGURE 1 | A model illustrating the putative roles of $M \phi$ polarization and $B$-cell involvement during the formation and function of TB granulomas. TB granuloma $M \phi s$ undergo various specialized transformations: they can look like epithelial characterized by tightly interdigitated cell membranes that link adjacent cells; they can fuse into multinucleated giant cells; or they can differentiate into foamy cells with a high content of intracellular lipids. While none of these specialized transformations in the granuloma $M \phi$ population are well understood, we propose they might be reflection of the $M \phi$ polarization status that may render the granuloma structure with a microbicidal capacity (top) or as a tool of pathogenesis (bottom). In the former scenario, the local M $\phi$ population in lung undergoes a M1 polarization early on during Mtb infection and granuloma formation, distinguished by a cell-surface receptor repertoire responsive to pro-inflammatory signaling (e.g., IFN- $\gamma R^{\text {high }}$ ) and conducive for antigen-presentation (e.g., MHC-Il' high, CD86 high), while acquiring a microbicidal capacity reflected in the NO production (e.g., iNOS ${ }^{\text {high }}$, ASS1 ${ }^{\text {positive }}$ ), among others. These M $\phi s$ have been noted to be most frequently located in the necrotic center of a mature tuberculous granuloma where apoptotic and necrotic $\mathrm{M} \phi s$ are abundant along with extracellular bacteria. Accompanying the M1 M $\phi$ polarization is the recruitment of neutrophils and Th1 cells, whose migration and activation status might be influenced by a B-cell involvement likely characterized by a pro-inflammatory phenotype (e.g., IFN- $\gamma^{\text {high }} / \mathrm{L}-6^{\text {high }}\left(\mathrm{gG}^{\text {high }}\right)$. In the latter scenario, we propose a change in the TB granuloma environment during the late stages of Mtb infection, distinguished by the M2 M polarization driven by the high expression of transcription factors (e.g., PPAR $\gamma^{\text {high }}$, STAT6 ${ }^{\text {positive }}$ ) antagonistic for type-1 inflammation, and characterized by a cell-surface receptor repertoire promoting tissue repair activities (e.g., IL-4R $\mathrm{R}^{\text {high }}$ ) and the formation of foamy cells (e.g., CD36 high), while suppressing the microbicidal functions like NO production (e.g., ARG $1^{\text {high }}$ ), among others. We envision M2 M申 polarization might give rise to the formation of foam and multinucleated giant cells, whose presence is noted to be most frequently at the rim and center of mature TB granulomas, and which may favor the intracellular resilience of Mtb. Furthermore, classical M2 M $\phi$ s have been noted to be most frequently located surrounding the granuloma center and overwhelmingly in the local lung environment. Along with the M2 M $\phi$ polarization is the inhibition of neutrophil recruitment while enhancing that of $T_{\text {regs }}$, activities that might be influenced by a B-cell involvement likely characterized by a anti-inflammatory phenotype (e.g., IL-10 high, CD1 $\left.\mathrm{d}^{\text {positive }}\right)$.
(Mahajan et al., 2012). Here, we postulate that factors governing M2 polarization establish additional anti-inflammatory signaling loops, like that of CD36, to increase microbial fitness within granulomas (Kuda et al., 2011). Third, the shift toward M2 Mфs may allow Mtb to control the antigen-presentation process to undermine adaptive immunity within granulomas (Benoit et al., 2008). Indeed, TB granulomas display a limited antigen-presentation to evoke significant T-cell responses (Egen et al., 2011). While $\mathrm{M} \phi$ polarization was not addressed in this study, M2 M $\phi$ s do inhibit the proliferation of CD4 T-cells while fomenting the activity of regulatory T-cells (Schebesch et al., 1997; Curiel et al., 2004; Biswas and Mantovani, 2010). Altogether, the shift toward M2 M $\phi$ s might also occur in human granulomas and contribute to Mtb pathogenesis given that TB susceptibility is often accompanied by elevated 
type-2 inflammatory and immunosuppressant signals (Kahnert et al., 2006; Raju et al., 2008; Almeida et al., 2009; Schreiber et al., 2009).

In the near future, we envision the role of $M \phi$ polarization in the granuloma context will be tested directly in different ways. First, we expect further advances in real-time imaging in both zebrafish and mouse models. Highly conserved $\mathrm{M} \phi$ polarization markers are ideal candidates for the development of novel animal reporter lines expressing different fluorochromes to target the different $M \phi$ subsets. Second, specific gene inactivation of $M \phi$ polarization markers with the use of morpholinos (in zebrafish), siRNA-based technology, or gene-knockout strategy (including conditional strategies), may be used at different stages of granuloma formation in animal models. The strategies above could be used in combination with global array-based transcriptomics and proteomics approaches in order to assess the granuloma and local lung environment in the presence or absence of $\mathrm{M} \phi$ subsets. Collectively, we expect there would be more future efforts to bridge results obtained in animals into the human context as discussed in the conclusion section.

\section{A ROLE FOR B-CELLS IN GRANULOMATOUS DISEASES}

Alterations in the lung environment by Mtb and/or subsequent immune responses likely affect the infection outcome. None of these is more apparent than the type- 1 inflammatory storm that is unleashed in murine lungs at 3 week p.i., when a peak of IFN$\gamma /$ TNF coincides with CD4 ${ }^{+}$T-cell involvement, an event that impacts the organization of nascent granuloma structures. Yet, mice in which $\mathrm{CD} 4^{+} \mathrm{T}$-cells are unable to produce IFN- $\gamma / \mathrm{TNF}$ are still resistant to $\mathrm{TB}$, suggesting a complex scenario for protection (Torrado and Cooper, 2011). In this perspective article, we propose that, beside T-cells, B-cells modulate the TB granuloma formation and function through interaction with their cellular components.

Despite extensive evidence for anti-Mtb antibody production in TB patients (Kunnath-Velayudhan et al., 2010, 2012), and a higher susceptibility of pIgR (IgA receptor)-deficient mice (Tjarnlund et al., 2006), initial studies examining the role of antibodies in $\mathrm{TB}$ indicated a modest impact in protective immunity, with benefits limited to passive administration of anti-Mtb antibodies (Glatman-Freedman and Casadevall, 1998; Roy et al., 2005; Abebe and Bjune, 2009). This contributed to the notion B-cells played a minor role in TB immunity, if any. Yet, recent studies now provide compelling reasons to revisit the role of B-cells in TB (Cooper, 2009; Maglione and Chan, 2009; Flynn et al., 2011; Philips and Ernst, 2012). First, B-cells infiltrate the lungs of Mtb-infected mice and humans (Tsai et al., 2006), where they organize in ectopic Bcell follicles at the periphery of granulomas (Gonzalez-Juarrero et al., 2001; Ulrichs et al., 2004; Kahnert et al., 2007; Maglione et al., 2007). These foci are the predominant sites of cellular proliferation in the infected lungs attesting to the importance of B-cells in shaping the local environment during infection (Ulrichs et al., 2004). Moreover, B-cells also infiltrate the granuloma structure, as shown in non-human primates where activated B-cell clusters are found in close contact with T-cells (Phuah et al., 2012), and in the lungs from cattle with natural tuberculosis (Beytut, 2011). Mtbspecific B-cells also exist at local sites of infection in pleural fluids, a strategic place to influence the immunity against $\mathrm{Mtb}$ (Feng et al., 2011). Beyond TB, B-cells are well-known cellular components in

Table 1 | Characteristics of B-cells identified in non-TB granulomatous diseases.

\begin{tabular}{|c|c|c|c|c|}
\hline Disease or model & Type of B-cells & Reported role in disease & Specie & Reference \\
\hline Wegener's granuloma & Undefined & Detrimental & Humans & Voswinkel et al. (2008), Holle et al. (2012) \\
\hline Sarcoidosis & Undefined & Unknown & Humans & Fukuda et al. (1997) \\
\hline Churg-Strauss syndrome & Undefined & Detrimental & Humans & Donvik and Omdal (2011) \\
\hline Crohn's disease & $\mathrm{B} 1^{\mathrm{a}}$ & Unknown & Humans & Geboes et al. (1986) \\
\hline Schistosomiasis & Undefined & $\begin{array}{l}\text { Favor protective Th2 immunity; inhibit } \\
\text { T-cell-mediated immunopathology; } \\
\text { granuloma formation }\end{array}$ & Mouse & $\begin{array}{l}\text { Hernandez et al. (1997, Ferru), Jankovic } \\
\text { et al. (1998), Jacobs et al. (1999), Ji et al. } \\
\text { (2008) }\end{array}$ \\
\hline Leishmaniasis & $\begin{array}{l}\text { Include } \mathrm{B} 2^{\mathrm{b}} \text { as well as } \\
\mathrm{CD} 5^{+} \mathrm{CD} 1 \mathrm{~d}^{+} \mathrm{IL}-10 \text { producing } \\
\text { regulatory Breg }{ }^{\mathrm{C}} \text { cells }\end{array}$ & $\begin{array}{l}\text { Limits immunopathology; favor } \\
\text { protective Th2 immunity; favor } \\
\text { granuloma formation }\end{array}$ & Mouse & $\begin{array}{l}\text { Smelt et al. (2000), Ronet et al. (2010), } \\
\text { Moore et al. (2012) }\end{array}$ \\
\hline Coccidioidomycosis & IL-10 producing $B_{\text {regs }}$ & Unknown & Humans & Li et al. (2005) \\
\hline Paracoccidiois & B1, IL-10 producing $B_{\text {regs }}$ & Detrimental & Mouse & Popi et al. (2008) \\
\hline Cat-scratch disease & IL-10 producing $B_{\text {regs }}$ & Unknown & Humans & Vermi et al. (2006) \\
\hline $\begin{array}{l}\text { Pristane induced oil } \\
\text { granuloma response }\end{array}$ & Undefined & Granuloma formation & Mouse & Chen et al. (2010) \\
\hline
\end{tabular}

${ }^{a} B 1$ cells: developmentally defined; innate-like B-cells in the mouse; $C D 5^{+}$or $C D 5^{-}$subpopulation poorly defined in humans.

${ }^{b}$ B2 cells: developmentally defined; include "conventional" follicular B-cells as well as "innate-like" marginal zone B-cells.

${ }^{c} B_{\text {regs }}$ : functionally defined; present among various B-cell populations including $C D 5^{+} C D 1 d^{+} B$-cells; can produce IL-10. 
several other granulomatous diseases (Table 1). Not only B-cells are present in granuloma but also they could be important for their maturation. This is suggested in pristane induced oil granuloma formation (Chen et al., 2010) and during Schistosoma japonicum infection (Ji et al., 2008) where the absence of B-cells results in a marked delay in granuloma formation. In the context of the TB, although granulomas form in the absence of B-cells, their numbers and size remain lower and they hardly become inflammatory (Bosio et al., 2000; Maglione et al., 2007). This could be the result of the well-known ability of B-cells to contribute to the organization of secondary and tertiary lymphoid organs (Moseman et al., 2012).

Second, although this is a rare event, occurrence of mycobacterial infections was reported upon rituximab-mediated depletion of B-cells, suggesting a protective role for these lymphocytes (Winthrop et al., 2008; Gea-Banacloche, 2010). However, other granulomatous diseases were successfully treated with rituximab (Donvik and Omdal, 2011; Holle et al., 2012), cautioning B-cells may be detrimental depending on the disease context. Finally, beyond antibody production, B-cells display diverse roles in the immunity against multiple pathogens that could operate during TB. In this regard, Salmonella infection, though not occasioning granuloma formation, represents a paradigm for antibodyindependent roles of B-cells against an intracellular bacterium with the evidence that B-cells producing IL-10 ( $\left.\mathrm{B}_{\text {regs }}\right)$ impairs the control of natural and vaccine-induced immunity to Salmonella (Neves et al., 2010). Since this role cannot simply be recapitulated in animal models lacking B-cells (Mastroeni et al., 2000; Mittrucker et al., 2000), this exemplifies how deletion of the B-cell compartment eclipses specific functions of these cells.

$\mathrm{B}$-cells express adaptive and innate receptors to recognize pathogens (Blumenthal et al., 2009; Rawlings et al., 2012). Beyond antibody production, B-cells secrete various signals including cytokines, and serve as antigen-presenting cells (Rawlings et al., 2012). These immune-modulatory functions are performed by different B-cell subsets depending on their differentiation program (e.g., B1, B2), activation status (e.g., naïve, effector, memory), tissue distribution, the timing of the immune response, or disease context. From this perspective, the identity of B-cells infiltrating the lungs of $\mathrm{TB}$ patients or animals remains relatively unknown. In most cases, these cells (likely B2-cells) have undergone class switch recombination and produce antibodies (Phuah et al., 2012). However, $\mathrm{CD}^{+} \mathrm{CD}^{+} \mathrm{d}^{+} \mathrm{B} 1$-cells are also observed predominantly in TB patients (Zhang et al., 2012) and in mouse models of TB and other granulomatous diseases (Li et al., 2005; Popi et al., 2008; Ronet et al., 2010). Regardless of their identity or individual contribution, we estimate the B-cell compartment influences the TB granuloma formation and function through interaction with $\mathrm{M} \phi \mathrm{s}$, T-cells, and neutrophils (Figure 1).

As B-cells interact with $\mathrm{M} \phi \mathrm{s}$ in $\mathrm{TB}$ granulomas (Tsai et al., 2006; Chakravarty et al., 2008), they might affect M $\phi$ polarization within these structures. A case in point, B1-cells differentiate M2 M申s via IL-10 in vitro and in a tumor model (Wong et al., 2010). However, mice deficient for B1-cells (xid model) displayed rather a susceptibility to mycobacterial infection, accompanied by increased levels of IL-10 (Junqueira-Kipnis et al., 2005; Russo and Mariano, 2010). Certainly, there are other B-cell subsets that could compensate as the in vivo source of IL-10, like $\mathrm{B}_{\text {regs }}$ (O'Garra et al., 1990; Lampropoulou et al., 2008). Likewise, there exist alternative in vivo immunosuppressive mechanisms driven by B-cells other than the B1-cell subset, as demonstrated for IgG production favoring FcR-mediated M2 M $\phi$ polarization in a carcinoma model (Andreu et al., 2010). In line with this observation, FC $\gamma$ RIIBdeficient M $\phi$ s displayed a M1 M $\phi$ phenotype upon Mtb infection, express less IL-10 and better control the infection (Maglione et al., 2008). Since the phenotype manifests after 3 weeks of infection, IgG-producing B2-cells produced during the course of the adaptive immune response might be involved. B1 cells might rather contribute to M2 polarization through Fc $\gamma$ R-independent IL-10dependant mechanisms. Whether these events occur within the granuloma is currently unknown. Collectively, these studies infer a B-cell contribution to an immunosuppressive niche within TB granulomas by tilting $\mathrm{M} \phi$ s toward the $\mathrm{M} 2$ program.

If $\mathrm{M} \phi s$ are the main components in nascent $\mathrm{TB}$ granulomas, then $\mathrm{CD}^{+}{ }^{+} \mathrm{T}$-cells are perhaps the most critical component of stable TB granulomas as shown by the re-awakening of latent TB in HIV-1 co-infected patients. In recent years, multiple studies suggest an immune-modulatory role for B-cells in T-cell activity at the granuloma level. On one hand, B-cells can co-localize with T-cells in TB granulomas (Ulrichs et al., 2004; Beytut, 2011), and directly interact with them in the granulomas caused by Leishmania (Moore et al., 2012). On the other hand, B-cells influence T-cell effector functions either through cytokine production or antigen-presentation (Lund and Randall, 2010). In TB context, IL-10 derived from B1-cells controls the homeostasis of T-helper-17 (Th17), essential for anti-microbial immunity at epithelial/mucosal barriers (Zhang et al., 2012). Reciprocally, Th-17-associated cytokines promote the formation of B-cell foci in Mtb-infected mice, and correlate with B-cell infiltration in TB patients (Khader et al., 2011; Zhang et al., 2011). In the mouse model, IL-17A (Okamoto Yoshida et al., 2010) or IL-23-deficient (Khader et al., 2011; Zhang et al., 2011) animals have marked defects in the formation of granulomas and/or B-cell follicles. In addition IL-23-deficient mice also have poor levels of IL-17 and IL22. These deficiencies resulted in a marked alteration of CXCL13 production, the chemokine responsible for B-cell recruitment and follicle formation (Khader et al., 2011; Zhang et al., 2011). It is not known if IL-10 production by B-cells is at the initiation or a secondary consequence of the alterations in IL-17 levels. These observations might provide an explanation for the links reported in TB patients between Th17 and formation of B-cell foci and IL-10 (Zhang et al., 2011, 2012).

Evidence obtained in non-TB diseases argue B-cells favor Th1 polarization (involved in TB protective immunity) through IL6 and IFN- $\gamma$ production during Salmonella infection, or promote Th2 differentiation (thought to be detrimental during TB) through either IL-2 (Wojciechowski et al., 2009) or IL-10 (Ferru et al., 1998; Popi et al., 2008; Ronet et al., 2010) in the control of different parasites. Conversely, B-cells also suppress T-cell activity as best illustrated in mice with a targeted deletion of MyD88 in B-cells during Salmonella infection (Neves et al., 2010). Finally, evidencing the role of B-cells as antigen-presenting cells, mice with a targeted deletion of MHC-II in B-cells displayed a reduction of IL- 2 and IFN- $\gamma$ by $\mathrm{CD}^{+}$memory T-cells during 
Salmonella challenge (Barr et al., 2010), and low pulmonary Th1 cell counts during Pneumocystis infection (Lund and Randall, 2010).

Another cell influencing TB granuloma formation is the neutrophil, whose migration can be controlled by B-cells. During Salmonella infection, mice with a targeted deletion of MyD88 in B-cells exhibited an accumulation of neutrophils in the spleen, an effect that likely depends on $\mathrm{B}_{\text {regs }}$-mediated IL-10 production (Neves et al., 2010). In the context of mycobacterial infections, aberrant neutrophil migration is known to have deleterious effects in host tissue integrity (Eruslanov et al., 2005; Berry et al., 2010). In mice deficient for the B-cell compartment (Maglione et al., 2007), Mtb infection leads to an uncontrolled accumulation of pulmonary neutrophils, an observation also supported by the excessive neutrophil migration in the peritoneum after BCGvaccination (Kondratieva et al., 2010). These examples highlight the importance of tolerance mechanisms in TB.

Based on the above observation, it is tempting to propose that B-cell could act at different levels during TB such as during granuloma progression and by influencing the effector function of third-party cells like M $\phi$ s. To directly examine this, studying B-cell contribution through comparison of B-cell-competent vs. B-cell-deficient animals should now be further complemented by studies examining the direct response of B-cells to Mtb infection, and through analyses in animal models lacking specific pathways in B-cells and biological consequences.

\section{REFERENCES}

Abebe, F., and Bjune, G. (2009). The protective role of antibody responses during Mycobacterium tuberculosis infection. Clin. Exp. Immunol. 157, 235-243.

Adams, D. O. (1974). The structure of mononuclear phagocytes differentiating in vivo. I. Sequential fine and histologic studies of the effect of Bacillus CalmetteGuerin (BCG). Am. J. Pathol. 76, 17-48.

Aggad, D., Stein, C., Sieger, D., Mazel, M., Boudinot, P., Herbomel, P., et al. (2010). In vivo analysis of Ifngammal and Ifn-gamma2 signaling in zebrafish. J. Immunol. 185, 6774-6782.

Almeida, A. S., Lago, P. M., Boechat, N., Huard, R. C., Lazzarini, L. C., Santos, A. R., et al. (2009). Tuberculosis is associated with a down-modulatory lung immune response that impairs Th1-type immunity. J. Immunol. 183, 718-731.

Andreu, P., Johansson, M., Affara, N. I., Pucci, F., Tan, T., Junankar, S., et al. (2010). FcRgamma activation regulates inflammation-associated squamous carcinogenesis. Cancer Cell 17, 121-134.

Balla, K. M., Lugo-Villarino, G., Spitsbergen, J. M., Stachura, D.

\section{CONCLUSION}

Among trends emerging in TB etiology, the notion that the local lung environment shifts from a host-protective nature toward one favorable to microbial resilience is discussed here at the granuloma level and in the context of $M \phi$ polarization and B-cell function (see also an illustration in Figure 1). Exploring these issues will likely bring us closer to uncover the enigma concealed by TB granulomas. One can envisage that studies investigating the role of genes involved in host tolerance (Medzhitov et al., 2012) might be a good way to explore these aspects of the disease. Although in humans this could be limited to immunogenetic studies, more mechanistic studies could be conducted in animal models where selective inactivation of those genes could provide new insights on the consequences on the pathology. These studies could go along with more sophisticated approaches based on single cell analysis such as those involving laser microdissection or more global phenotypic signatures obtained from mass cytometry, in order to further identify cell subsets involved at different stages of granuloma formation and TB.

\section{ACKNOWLEDGMENTS}

The authors received no specific funding for this work. The Neyrolles laboratory is supported by the CNRS, the European Union (7th Framework Programme and ERA-NET), Agence Nationale de la Recherche, Fondation pour la Recherche Médicale (FRM), and Fondation Mérieux. Geanncarlo Lugo-Villarino and A. Benard are supported by fellowships from FRM.

Blumenthal, A., Kobayashi, T., Pierini, L. M., Banaei, N., Ernst, J. D., Miyake, K., et al. (2009). RP105 facilitates macrophage activation by Mycobacterium tuberculosis lipoproteins. Cell Host Microbe 5, 35-46.

Bosio, C. M., Gardner, D., and Elkins, K. L. (2000). Infection of B celldeficient mice with CDC 1551, a clinical isolate of Mycobacterium tuberculosis: delay in dissemination and development of lung pathology. J. Immunol. 164, 6417-6425.

Cairo, G., Recalcati, S., Mantovani, A., and Locati, M. (2011). Iron trafficking and metabolism in macrophages: contribution to the polarized phenotype. Trends Immunol. 32, 241-247.

Chakravarty, S. D., Zhu, G., Tsai, M. C. Mohan, V. P., Marino, S., Kirschner, D. E., et al. (2008). Tumor necrosis factor blockade in chronic murine tuberculosis enhances granulomatous inflammation and disorganizes granulomas in the lungs. Infect. Immun. 76, 916-926.

Chan, J., Xing, Y., Magliozzo, R. S., and Bloom, B. R. (1992). Killing of virulent Mycobacterium tuberculosis by reactive nitrogen intermediates produced by activated murine macrophages. J. Exp. Med. 175, 1111-1122.
Chen, H., Liao, D., Holl, T. M. Snowden, P., Ueda, Y., and Kelsoe, G. (2010). Genetic regulation of pristane-induced oil granuloma responses. Int. J. Exp. Pathol. 91, 472-483.

Choi, H. S., Rai, P. R., Chu, H. W., Cool, C., and Chan, E. D. (2002). Analysis of nitric oxide synthase and nitrotyrosine expression in human pulmonary tuberculosis. Am. J. Respir. Crit. Care Med. 166, 178-186.

Cooper, A. M. (2009). Cell-mediated immune responses in tuberculosis. Annu. Rev. Immunol. 27, 393-422.

Curiel, T. J., Coukos, G., Zou, L., Alvarez, X., Cheng, P., Mottram, P., et al. (2004). Specific recruitment of regulatory $\mathrm{T}$ cells in ovarian carcinoma fosters immune privilege and predicts reduced survival. Nat. Med. 10, 942-949.

Davis, J. M., Clay, H., Lewis, J. L., Ghori, N., Herbomel, P., and Ramakrishnan, L. (2002). Real-time visualization of mycobacterium-macrophage interactions leading to initiation of granuloma formation in zebrafish embryos. Immunity 17, 693-702.

Davis, J. M., and Ramakrishnan, L. (2009). The role of the granuloma in expansion and dissemination of early tuberculous infection. Cell 136, 37-49. 
Deretic, V., Vergne, I., Chua, J., Master, S., Singh, S. B., Fazio, J. A., et al. (2004). Endosomal membrane traffic: convergence point targeted by Mycobacterium tuberculosis and HIV. Cell. Microbiol. 6, 999-1009.

Donvik, K. K., and Omdal, R. (2011). Churg-Strauss syndrome successfully treated with rituximab. Rheumatol. Int. 31, 89-91.

Dorhoi, A., Reece, S. T., and Kaufmann, S. H. (2011). For better or for worse: the immune response against Mycobacterium tuberculosis balances pathology and protection. Immunol. Rev. 240, 235-251.

Egen, J. G., Rothfuchs, A. G., Feng, C. G., Horwitz, M. A., Sher, A., and Germain, R. N. (2011). Intravital imaging reveals limited antigen presentation and $\mathrm{T}$ cell effector function in mycobacterial granulomas. Immunity 34, 807-819.

Ehrt, S., Schnappinger, D., Bekiranov, S., Drenkow, J., Shi, S., Gingeras, T. R., et al. (2001). Reprogramming of the macrophage transcriptome in response to interferon-gamma and Mycobacterium tuberculosis: signaling roles of nitric oxide synthase-2 and phagocyte oxidase. J. Exp. Med. 194, 1123-1140.

El Kasmi, K. C., Qualls, J. E., Pesce, J. T., Smith, A. M., Thompson, R. W., Henao-Tamayo, M., et al. (2008). Toll-like receptor-induced arginase 1 in macrophages thwarts effective immunity against intracellular pathogens. Nat. Immunol. 9, 1399-1406.

Eruslanov, E. B., Lyadova, I. V., Kondratieva, T. K., Majorov, K. B., Scheglov, I. V., Orlova, M. O., et al. (2005). Neutrophil responses to Mycobacterium tuberculosis infection in genetically susceptible and resistant mice. Infect. Immun. 73, 1744-1753.

Facchetti, F., Vermi, W., Fiorentini, S., Chilosi, M., Caruso, A., Duse, M., et al. (1999). Expression of inducible nitric oxide synthase in human granulomas and histiocytic reactions. Am. J. Pathol. 154, 145-152.

Feng, L., Li, L., Liu, Y., Qiao, D., Li, Q., Fu, X., et al. (2011). B lymphocytes that migrate to tuberculous pleural fluid via the SDF-1/CXCR4 axis actively respond to antigens specific for Mycobacterium tuberculosis. Eur. J. Immunol. 41, 3261-3269.

Ferru, I., Roye, O., Delacre, M., Auriault, C., and Wolowczuk, I. (1998). Infection of B-cell-deficient mice by the parasite Schistosoma mansoni: demonstration of the participation of B cells in granuloma modulation. Scand. J. Immunol. 48, 233-240.
Flynn, J. L. (2006). Lessons from experimental Mycobacterium tuberculosis infections. Microbes Infect. 8, 1179-1188.

Flynn, J. L., Chan, J., and Lin, P. L. (2011). Macrophages and control of granulomatous inflammation in tuberculosis. Mucosal Immunol. 4, 271-278.

Flynn, J. L., Chan, J., Triebold, K. J., Dalton, D. K., Stewart, T. A., and Bloom, B. R. (1993). An essential role for interferon gamma in resistance to Mycobacterium tuberculosis infection. J. Exp. Med. 178, 2249-2254.

Forbes, J. R., and Gros, P. (2001). Divalent-metal transport by NRAMP proteins at the interface of host-pathogen interactions. Trends Microbiol. 9, 397-403.

Fukuda, T., Sato, K., Tachikawa, S., Ohnuki, K., Ohtani, H., and Suzuki, T. (1997). Mucosa-associated lymphoid tissue lymphoma coexisting with epithelioid granulomas in the stomach of a patient with systemic sarcoidosis. Pathol. Int. 47, 870-875.

Gea-Banacloche, J. C. (2010). Rituximab-associated infections. Semin. Hematol. 47, 187-198.

Geboes, K., Van Den Oord, J., De Wolf-Peeters, C., Desmet, V., Rutgeerts, P., Janssens, J., et al. (1986). The cellular composition of granulomas in mesenteric lymph nodes from patients with Crohn's disease. Virchows Arch. A Pathol. Anat. Histopathol. 409, 679-692.

Glatman-Freedman, A., and Casadevall, A. (1998). Serum therapy for tuberculosis revisited: reappraisal of the role of antibody-mediated immunity against Mycobacterium tuberculosis. Clin. Microbiol. Rev. 11, 514-532.

Goerdt, S., and Orfanos, C. E. (1999). Other functions, other genes: alternative activation of antigenpresenting cells. Immunity 10, 137-142.

Gonzalez-Juarrero, M., Turner, O. C., Turner, J., Marietta, P., Brooks, J. V., and Orme, I. M. (2001). Temporal and spatial arrangement of lymphocytes within lung granulomas induced by aerosol infection with Mycobacterium tuberculosis. Infect. Immun. 69, 1722-1728.

Gordon, S. (2003). Alternative activation of macrophages. Nat. Rev. Immunol. 3, 23-35.

Griffin, J. E., Gawronski, J. D., Dejesus, M. A., Ioerger, T. R., Akerley, B. J., and Sassetti, C. M. (2011). High-resolution phenotypic profiling defines genes essential for mycobacterial growth and cholesterol catabolism. PLoS Pathog. 7:e1002251. doi:10.1371/journal.ppat.1002251

Helming, L., and Gordon, S. (2007). The molecular basis of macrophage fusion. Immunobiology 212, 785-793.

Hernandez, H. J., Wang, Y., and Stadecker, M. J. (1997). In infection with Schistosoma mansoni, B cells are required for $\mathrm{T}$ helper type 2 cell responses but not for granuloma formation. J. Immunol. 158 4832-4837.

Holle, J. U., Dubrau, C., Herlyn, K., Heller, M., Ambrosch, P., Noelle, B., et al. (2012). Rituximab for refractory granulomatosis with polyangiitis (Wegener's granulomatosis): comparison of efficacy in granulomatous versus vasculitic manifestations. Ann. Rheum. Dis. 71, 327-333.

Holt, A., Mitra, S., Van Der Sar, A. M., Alnabulsi, A., Secombes, C. J. and Bird, S. (2011). Discovery of zebrafish (Danio rerio) interleukin23 alpha (IL-23alpha) chain, a subunit important for the formation of IL-23, a cytokine involved in the development of Th17 cells and inflammation. Mol. Immunol. 48, 981-991.

Jacobs, W., Bogers, J., and Van Marck, E. (1999). Distinct B-cell populations are present in hepatic and intestinal Schistosoma mansoni granulomas. Acta Gastroenterol. Belg. 62, 178-181.

Jankovic, D., Cheever, A. W., Kullberg, M. C., Wynn, T. A., Yap, G., Caspar, P., et al. (1998). CD4+ T cellmediated granulomatous pathology in schistosomiasis is downregulated by a $\mathrm{B}$ cell-dependent mechanism requiring $\mathrm{Fc}$ receptor signaling. J. Exp. Med. 187, 619-629.

Ji, F., Liu, Z., Cao, J., Li, N., Zuo, J. Chen, Y., et al. (2008). B cell response is required for granuloma formation in the early infection of Schistosoma japonicum. PLoS ONE 3:e1724. doi:10.1371/journal.pone.0001724

Junqueira-Kipnis, A. P., Kipnis, A., Henao Tamayo, M., Harton, M., Gonzalez Juarrero, M., Basaraba, R. J., et al. (2005). Interleukin-10 production by lung macrophages in CBA xid mutant mice infected with Mycobacterium tuberculosis. Immunology 115, 246-252.

Kahnert, A., Hopken, U. E., Stein, M., Bandermann, S., Lipp, M., and Kaufmann, S. H. (2007). Mycobacterium tuberculosis triggers formation of lymphoid structure in murine lungs. J. Infect. Dis. 195, 46-54.

Kahnert, A., Seiler, P., Stein, M., Bandermann, S., Hahnke, K., Mollenkopf,
H., et al. (2006). Alternative activation deprives macrophages of a coordinated defense program to Mycobacterium tuberculosis. Eur. J. Immunol. 36, 631-647.

Khader, S. A., Guglani, L., RangelMoreno, J., Gopal, R., Junecko, B. A., Fountain, J. J., et al. (2011). IL-23 is required for long-term control of Mycobacterium tuberculosis and B cell follicle formation in the infected lung. J. Immunol. 187, 5402-5407.

Koch, R. (1982). [The etiology of tuberculosis by Dr. Robert Koch. From the Berliner Klinische Wochenschrift, Volume 19 (1882)]. Zentralbl. Bakteriol. Mikrobiol. Hyg. A 251, 287-296.

Kondratieva, T. K., Rubakova, E. I., Linge, I. A., Evstifeev, V. V., Majorov, K. B., and Apt, A. S. (2010). B cells delay neutrophil migration toward the site of stimulus: tardiness critical for effective bacillus CalmetteGuerin vaccination against tuberculosis infection in mice. J. Immunol. 184, 1227-1234.

Kuda, O., Jenkins, C. M., Skinner, J. R., Moon, S. H., Su, X., Gross, R. W., et al. (2011). CD36 protein is involved in store-operated calcium flux, phospholipase A2 activation, and production of prostaglandin E2. J. Biol. Chem. 286, 17785-17795.

Kunnath-Velayudhan, S., Davidow, A. L., Wang, H. Y., Molina, D. M., Huynh, V. T., Salamon, H., et al. (2012). Proteome-scale antibody responses and outcome of Mycobacterium tuberculosis infection in nonhuman primates and in tuberculosis patients. J. Infect. Dis. 206, 697-705.

Kunnath-Velayudhan, S., Salamon, H., Wang, H. Y., Davidow, A. L., Molina, D. M., Huynh, V. T., et al. (2010). Dynamic antibody responses to the Mycobacterium tuberculosis proteome. Proc. Natl. Acad. Sci. U.S.A. 107, 14703-14708.

Lampropoulou, V., Hoehlig, K., Roch, T., Neves, P., Calderon Gomez, E., Sweenie, C. H., et al. (2008). TLR-activated B cells suppress $\mathrm{T}$ cell-mediated autoimmunity. J. Immunol. 180, 4763-4773.

Lawrence, T., and Natoli, G. (2011). Transcriptional regulation of macrophage polarization: enabling diversity with identity. Nat. Rev. Immunol. 11, 750-761.

Li, L., Dial, S. M., Schmelz, M., Rennels, M. A., and Ampel, N. M. (2005). Cellular immune suppressor activity resides in lymphocyte cell clusters adjacent to granulomata in human coccidioidomycosis. Infect. Immun. 73, 3923-3928. 
Lund, F. E., and Randall, T. D. (2010). Effector and regulatory $\mathrm{B}$ cells: modulators of CD4(+) T cell immunity. Nat. Rev. Immunol. 10, 236-247.

Maglione, P. J., and Chan, J. (2009). How $\mathrm{B}$ cells shape the immune response against Mycobacterium tuberculosis. Eur. J. Immunol. 39, 676-686.

Maglione, P. J., Xu, J., Casadevall, A., and Chan, J. (2008). Fc gamma receptors regulate immune activation and susceptibility during Mycobacterium tuberculosis infection. J. Immunol. 180, 3329-3338.

Maglione, P. J., Xu, J., and Chan, J. (2007). B cells moderate inflammatory progression and enhance bacterial containment upon pulmonary challenge with Mycobacterium tuberculosis. J. Immunol. 178, 7222-7234.

Mahajan, S., Dkhar, H. K., Chandra, V., Dave, S., Nanduri, R., Janmeja, A. K., et al. (2012). Mycobacterium tuberculosis modulates macrophage lipid-sensing nuclear receptors PPARgamma and TR4 for survival. J. Immunol. 188, 5593-5603.

Mantovani, A., Sica, A., Sozzani, S., Allavena, P., Vecchi, A., and Locati, M. (2004). The chemokine system in diverse forms of macrophage activation and polarization. Trends Immunol. 25, 677-686.

Martinez, F. O., Helming, L., and Gordon, S. (2009). Alternative activation of macrophages: an immunologic functional perspective. Annu. Rev. Immunol. 27, 451-483.

Mastroeni, P., Simmons, C., Fowler, R., Hormaeche, C. E., and Dougan, G. (2000). Igh-6(-/-) (B-cell-deficient) mice fail to mount solid acquired resistance to oral challenge with virulent Salmonella enterica serovar typhimurium and show impaired Th1 T-cell responses to Salmonella antigens. Infect. Immun. 68, 46-53.

Medzhitov, R., Schneider, D. S., and Soares, M. P. (2012). Disease tolerance as a defense strategy. Science 335, 936-941.

Mitra, S., Alnabulsi, A., Secombes, C. J., and Bird, S. (2010). Identification and characterization of the transcription factors involved in T-cell development, t-bet, stat6 and foxp3, within the zebrafish, Danio rerio. FEBS J. 277, 128-147.

Mittrucker, H. W., Raupach, B., Kohler, A., and Kaufmann, S. H. (2000). Cutting edge: role of B lymphocytes in protective immunity against Salmonella typhimurium infection. $J$. Immunol. 164, 1648-1652.

Moller, M., Nebel, A., Valentonyte, R., Van Helden, P. D., Schreiber, S., and Hoal, E. G. (2009). Investigation of chromosome 17 candidate genes in susceptibility to TB in a South African population. Tuberculosis 89, 189-194.

Moore, J. W., Beattie, L., Dalton, J. E., Owens, B. M., Maroof, A., Coles, M. C., et al. (2012). B cell: T cell interactions occur within hepatic granulomas during experimental visceral leishmaniasis. PLoS ONE 7:e34143. doi:10.1371/journal.pone.0034143

Moseman, E. A., Iannacone, M., Bosurgi, L., Tonti, E., Chevrier, N., Tumanov, A., et al. (2012). $B$ cell maintenance of subcapsular sinus macrophages protects against a fatal viral infection independent of adaptive immunity. Immunity 36, 415-426.

Munder, M., Eichmann, K., and Modolell, M. (1998). Alternative metabolic states in murine macrophages reflected by the nitric oxide synthase/arginase balance: competitive regulation by $\mathrm{CD} 4+\mathrm{T}$ cells correlates with Th1/Th2 phenotype. J. Immunol. 160, 5347-5354.

Murray, P. J., and Wynn, T. A. (2011a). Obstacles and opportunities for understanding macrophage polarization. J. Leukoc. Biol. 89, 557-563.

Murray, P. J., and Wynn, T. A. (2011b). Protective and pathogenic functions of macrophage subsets. Nat. Rev. Immunol. 11, 723-737.

Neves, P., Lampropoulou, V., CalderonGomez, E., Roch, T., Stervbo, U., Shen, P., et al. (2010). Signaling via the MyD88 adaptor protein in B cells suppresses protective immunity during Salmonella typhimurium infection. Immunity 33, 777-790.

Nicholson, S., Bonecini-Almeida Mda, G., Lapa e Silva, J. R., Nathan, C., Xie, Q. W., Mumford, R., et al. (1996). Inducible nitric oxide synthase in pulmonary alveolar macrophages from patients with tuberculosis. $J$. Exp. Med. 183, 2293-2302.

O'Garra, A., Stapleton, G., Dhar, V., Pearce, M., Schumacher, J., Rugo, H., et al. (1990). Production of cytokines by mouse B cells: B lymphomas and normal B cells produce interleukin 10. Int. Immunol. 2, 821-832.

Okamoto Yoshida, Y., Umemura, M., Yahagi, A., O’Brien, R. L., Ikuta, K., Kishihara, K., et al. (2010). Essential role of IL-17A in the formation of a mycobacterial infectioninduced granuloma in the lung. $J$. Immunol. 184, 4414-4422.

Pandey, A. K., and Sassetti, C. M. (2008). Mycobacterial persistence requires the utilization of host cholesterol. Proc. Natl. Acad. Sci. U.S.A. 105, 4376-4380.
Pessanha, A. P., Martins, R. A., MattosGuaraldi, A. L., Vianna, A., and Moreira, L. O. (2012). Arginase-1 expression in granulomas of tuberculosis patients. FEMS Immunol. Med. Microbiol. 66, 265-268.

Peyron, P., Vaubourgeix, J., Poquet, Y., Levillain, F., Botanch, C., Bardou, F. et al. (2008). Foamy macrophages from tuberculous patients' granulomas constitute a nutrient-rich reservoir for M. tuberculosis persistence. PLoS Pathog. 4:e1000204. doi:10.1371/journal.ppat.1000204

Philips, J. A., and Ernst, J. D. (2012). Tuberculosis pathogenesis and immunity. Annu. Rev. Pathol. 7, 353-384.

Phuah, J. Y., Mattila, J. T., Lin, P. L., and Flynn, J. L. (2012). Activated B cells in the granulomas of nonhuman primates infected with Mycobacterium tuberculosis. Am. J. Pathol. 181, 508-514.

Popi, A. F., Godoy, L. C., Xander, P., Lopes, J. D., and Mariano, M. (2008). B-1 cells facilitate Paracoccidioides brasiliensis infection in mice via IL-10 secretion. Microbes Infect. 10, 817-824.

Qualls, J. E., Neale, G., Smith, A. M., Koo, M. S., Defreitas, A. A., Zhang, H., et al. (2010). Arginine usage in mycobacteria-infected macrophages depends on autocrineparacrine cytokine signaling. Sci. Signal. 3, ra62.

Qualls, J. E., Subramanian, C., Rafi, W., Smith, A. M., Balouzian, L., Defreitas, A. A., et al. (2012). Sustained generation of nitric oxide and control of mycobacterial infection requires argininosuccinate synthase 1. Cell Host Microbe 12, 313-323.

Quintana-Murci, L., Alcais, A., Abel, L., and Casanova, J. L. (2007). Immunology in natura: clinical, epidemiological and evolutionary genetics of infectious diseases. Nat. Immunol. 8, 1165-1171.

Raju, B., Hoshino, Y., Belitskaya-Levy, I., Dawson, R., Ress, S., Gold, J. A. et al. (2008). Gene expression profiles of bronchoalveolar cells in pulmonary TB. Tuberculosis (Edinb.) 88, 39-51.

Ramakrishnan, L. (2012). Revisiting the role of the granuloma in tuberculosis. Nat. Rev. Immunol. 12, 352-366.

Rawlings, D. J., Schwartz, M. A., Jackson, S. W., and Meyer-Bahlburg, A. (2012). Integration of B cell responses through Toll-like receptors and antigen receptors. Nat. Rev. Immunol. 12, 282-294.

Redente, E. F., Higgins, D. M., DwyerNield, L. D., Orme, I. M., GonzalezJuarrero, M., and Malkinson, A.
M. (2010). Differential polarization of alveolar macrophages and bone marrow-derived monocytes following chemically and pathogeninduced chronic lung inflammation. J. Leukoc. Biol. 88, 159-168.

Renshaw, S. A., and Trede, N. S. (2012). A model 450 million years in the making: zebrafish and vertebrate immunity. Dis. Model Mech. 5, 38-47.

Ronet, C., Hauyon-La Torre, Y., RevazBreton, M., Mastelic, B., TacchiniCottier, F., Louis, J., et al. (2010). Regulatory B cells shape the development of Th2 immune responses in $\mathrm{BALB} / \mathrm{c}$ mice infected with Leishmania major through IL-10 production. J. Immunol. 184, 886-894.

Roy, E., Stavropoulos, E., Brennan, J., Coade, S., Grigorieva, E., Walker, B., et al. (2005). Therapeutic efficacy of high-dose intravenous immunoglobulin in Mycobacterium tuberculosis infection in mice. Infect. Immun. 73, 6101-6109.

Russell, D. G. (2007). Who puts the tubercle in tuberculosis? Nat. Rev. Microbiol. 5, 39-47.

Russell, D. G., Cardona, P. J., Kim, M. J., Allain, S., and Altare, F. (2009). Foamy macrophages and the progression of the human tuberculosis granuloma. Nat. Immunol. 10, 943-948.

Russo, R. T., and Mariano, M. (2010). B-1 cell protective role in murine primary Mycobacterium bovis bacillus Calmette-Guerin infection. Immunobiology 215, 1005-1014.

Sakula, A. (1982). Robert Koch: centenary of the discovery of the tubercle bacillus, 1882. Thorax 37, 246-251.

Schebesch, C., Kodelja, V., Muller, C., Hakij, N., Bisson, S., Orfanos, C. E., et al. (1997). Alternatively activated macrophages actively inhibit proliferation of peripheral blood lymphocytes and CD4+ $\mathrm{T}$ cells in vitro. Immunology 92, 478-486.

Schon, T., Elmberger, G., Negesse, Y., Pando, R. H., Sundqvist, T., and Britton, S. (2004). Local production of nitric oxide in patients with tuberculosis. Int. J. Tuberc. Lung Dis. 8, 1134-1137.

Schreiber, T., Ehlers, S., Heitmann, L., Rausch, A., Mages, J., Murray, P. J., et al. (2009). Autocrine IL10 induces hallmarks of alternative activation in macrophages and suppresses antituberculosis effector mechanisms without compromising T cell immunity. J. Immunol. 183, 1301-1312.

Shearer, J. D., Richards, J. R., Mills, C. D., and Caldwell, M. D. (1997). Differential regulation of macrophage 
arginine metabolism: a proposed role in wound healing. Am. J. Physiol. 272, E181-E190.

Sica, A., Larghi, P., Mancino, A., Rubino, L., Porta, C., Totaro, M. G., et al. (2008). Macrophage polarization in tumour progression. Semin. Cancer Biol. 18, 349-355.

Smelt, S. C., Cotterell, S. E., Engwerda, C. R., and Kaye, P. M. (2000). B celldeficient mice are highly resistant to Leishmania donovani infection, but develop neutrophil-mediated tissue pathology. J. Immunol. 164, 3681-3688.

Tjarnlund, A., Rodriguez, A., Cardona, P. J., Guirado, E., Ivanyi, J., Singh, M., et al. (2006). Polymeric IgR knockout mice are more susceptible to mycobacterial infections in the respiratory tract than wild-type mice. Int. Immunol. 18, 807-816.

Torrado, E., and Cooper, A. M. (2011). What do we really know about how CD4 T cells control Mycobacterium tuberculosis? PLoS Pathog. 7:e1002196. doi:10.1371/journal.ppat.1002196

Tsai, M. C., Chakravarty, S., Zhu, G., Xu, J., Tanaka, K., Koch, C., et al. (2006). Characterization of the tuberculous granuloma in murine and human lungs: cellular composition and relative tissue oxygen tension. Cell. Microbiol. 8, 218-232.

Ulrichs, T., Kosmiadi, G. A., Trusov, V., Jorg, S., Pradl, L., Titukhina, M., et al.
(2004). Human tuberculous granulomas induce peripheral lymphoid follicle-like structures to orchestrate local host defence in the lung. J. Pathol. 204, 217-228.

Vermi, W., Facchetti, F., Riboldi, E., Heine, H., Scutera, S., Stornello, S., et al. (2006). Role of dendritic cell-derived CXCL13 in the pathogenesis of Bartonella henselae B-rich granuloma. Blood 107, 454-462.

Volkman, H. E., Clay, H., Beery, D., Chang, J. C., Sherman, D. R., and Ramakrishnan, L. (2004). Tuberculous granuloma formation is enhanced by a mycobacterium virulence determinant. PLoS Biol. 2:e367. doi:10.1371/journal.pbio.0020367

Volkman, H. E., Pozos, T. C., Zheng, J., Davis, J. M., Rawls, J. F., and Ramakrishnan, L. (2010). Tuberculous granuloma induction via interaction of a bacterial secreted protein with host epithelium. Science 327, 466-469.

Voswinkel, J., Assmann, G., Held, G., Pitann, S., Gross, W. L., Holl-Ulrich, K., et al. (2008). Single cell analysis of B lymphocytes from Wegener's granulomatosis: B cell receptors display affinity maturation within the granulomatous lesions. Clin. Exp. Immunol. 154, 339-345.

Winthrop, K. L., Yamashita, S., Beekmann, S. E., and Polgreen, P. M. (2008). Mycobacterial and other serious infections in patients receiving anti-tumor necrosis factor and other newly approved biologic therapies: case finding through the Emerging Infections Network. Clin. Infect. Dis. 46, 1738-1740.

Wittamer, V., Bertrand, J. Y., Gutschow, P. W., and Traver, D. (2011). Characterization of the mononuclear phagocyte system in zebrafish. Blood 117, 7126-7135.

Wojciechowski, W., Harris, D. P., Sprague, F., Mousseau, B., Makris, M., Kusser, K., et al. (2009). Cytokine-producing effector B cells regulate type 2 immunity to $\mathrm{H}$. polygyrus. Immunity 30 421-433.

Wong, S. C., Puaux, A. L., Chittezhath, M., Shalova, I., Kajiji, T. S., Wang, X., et al. (2010). Macrophage polarization to a unique phenotype driven by B cells. Eur. J. Immunol. 40, 2296-2307.

Xie, Q. W., and Nathan, C. (1993). Promoter of the mouse gene encoding calcium-independent nitric oxide synthase confers inducibility by interferon-gamma and bacterial lipopolysaccharide. Trans. Assoc. Am. Physicians 106, 1-12.

Zhang, M., Wang, Z., Graner, M. W., Yang, L., Liao, M., Yang, Q., et al (2011). B cell infiltration is associated with the increased IL-17 and IL22 expression in the lungs of patients with tuberculosis. Cell. Immunol. 270, 217-223.
Zhang, M., Zheng, X., Zhang, J., Zhu, Y., Zhu, X., Liu, H., et al (2012). CD19(+)CD1d(+)CD5(+) $B$ cell frequencies are increased in patients with tuberculosis and suppress Th17 responses. Cell. Immunol. 274, 89-97.

Conflict of Interest Statement: The authors declare that the research was conducted in the absence of any commercial or financial relationships that could be construed as a potential conflict of interest.

Received: 05 October 2012; paper pending published: 03 November 2012; accepted: 15 December 2012; published online: 07 January 2013.

Citation: Lugo-Villarino G, Hudrisier D, Benard A and Neyrolles $O$ (2013) Emerging trends in the formation and function of tuberculosis granulomas. Front. Immun. 3:405. doi 10.3389/fimmu.2012.00405

This article was submitted to Frontiers in Inflammation, a specialty of Frontiers in Immunology.

Copyright (C) 2013 Lugo-Villarino, Hudrisier, Benard and Neyrolles. This is an open-access article distributed under the terms of the Creative Commons Attribution License, which permits use, distribution and reproduction in other forums, provided the original authors and source are credited and subject to any copyright notices concerning any third-party graphics etc. 